SECTION 21. Pedagogy. Psychology. Innovations in the field of education.

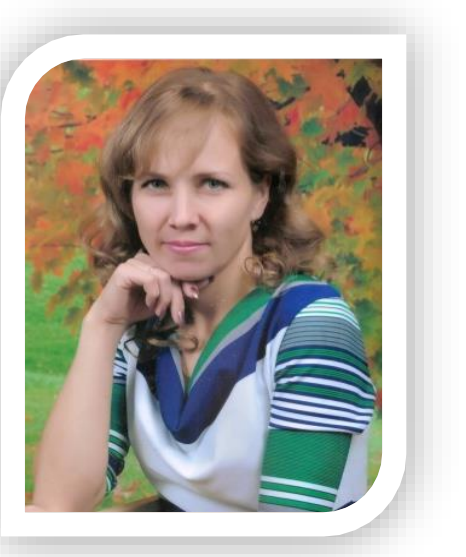

Gilmutdinova Nailya Vadimovna

The teacher of initial classes of the second category

Gymnasium №40, Taraz, Kazakhstan

\title{
EDUCATIONAL VALUE DIDACTIC GAMES IN TEACHING MATHEMATICS
}

Abstract: The paper considers the effectiveness and technique of didactic games in the process of teaching mathematics. Different aspects of the teaching process, as well as forms of the game approaches.

Key words: mathematics, education, didactics.

\section{ВОСПИТАТЕЛЬНОЕ ЗНАЧЕНИЕ ДИДАКТИЧЕСКИХ ИГР ПРИ ОБУЧЕНИИ МАТЕМАТИКЕ}

\begin{abstract}
Аннотация: B работе рассматривается эффективность и методика применения дидактических игр в процессе преподавания математики. Исследуются различные аспекты прочесса преподавания, а также формы игровых подходов.
\end{abstract}

Ключевые слова: математика, воспитание, дидактика.

Одним из эффективных средств развития интереса к учебному предмету наряду с другими методами и приёмами, используемыми на уроках, является дидактическая игра. Ещё К. Д. Ушинский советовал включать элементы занимательности, игровые моменты в серьезный учебный труд учащихся для того, чтобы процесс познания был более продуктивным [1].

В дошкольном возрасте игра имеет важнейшее значение в жизни ребенка. Она занимает значительное место в первые годы обучения детей в школе.

Вначале учащихся интересует только сама форма игры, а затем уже и тот материал, без которого невозможно участвовать в игре.

В процессе игры учащиеся незаметно для себя выполняют различные упражнения, где им приходится сравнивать множества, выполнять арифметические действия, тренироваться в устном счете, решать задачи. Игра ставит учащихся в условия поиска, пробуждает интерес к победе, а отсюда они стремятся быть быстрыми, собранными, ловкими, находчивыми, четко выполнять задания, соблюдая правила игры.

В играх, особенно коллективных, формируются и нравственные качества личности. Дети учатся оказывать помощь товарищам, считаться с интересами других. Сдерживать свои желания. У детей развивается чувство ответственности, коллективизма, воспитывается дисциплина, воля, характер [2].

Включение в урок игр и игровых моментов делает процесс обучения более интересным и занимательным, создает у детей бодрое, рабочее настроение, облегчает преодоление трудностей в усвоении учебного материала. Разнообразные игровые 
действия, при помощи которых решается та или иная умственная задача, поддерживают и усиливают интерес детей к учебному предмету, к познанию ими окружающего мира [2].

Шестилетний первоклассник в школе - эмоциональный ученик. Для него игра, сказка, выдумка - это неотъемлемая составляющая часть жизни. И учитель должен поддержать, пробудить в душе каждого интерес к познанию окружающего мира, зажечь огоньки детской мысли и творчества [3].

Для детей 1 класса математическая игра является привлекательной формой деятельности. Она дает ребенку информацию об окружающей действительности, предметах и их свойствах, явлениях, закономерностях, законах природы и общества, о человеке и, наконец, о самом себе [3].

Игра - творчество, игра - труд. Именно в играх начинается непринужденное общение ребенка с классным руководителем, возникает взаимопонимание между учителем и учеником. У детей вырабатывается привычка сосредотачиваться, работать вдумчиво, самостоятельно, в них развивается внимание, память, стремление к знаниям. Удовлетворяя свою естественную неустанную потребность в деятельности, ребенок, играя, «приобретает» в воображении то, что недоступно ему в реальной жизни. Увлекшись, он не замечает, что учится - познает, запоминает новое, ориентируется в необычных ситуациях, переносит и углубляет приобретенный ранее опыт, пополняет запас представлений, понятий, развивает фантазию [3].

Как известно, игра - один из самых эффективных средств возбуждения у учащихся интереса, положительных эмоций, развития фантазии, мышления, формирования понятий, выработки интеллектуально-практических умений и навыков, воспитание самостоятельности, настойчивости, расширение кругозора и т.д. [3]

В игровой деятельности наиболее полно раскрываются индивидуальные особенности каждого школьника. Игровые ситуации позволяют учителю легко привлечь внимание учащихся и в течение достаточно длительного времени поддерживать их интерес к важным и сложным предметам, свойствам и явлениям, на которых в обычных условиях сосредоточить внимание детей не всегда удается. Например, однообразное решение примеров утомляет их, вызывает безразличие к учебе. А уже решение этих самых примеров во время игры «Кто быстрее?», становится для детей увлекательным, интересным [3].

Дидактические игры на уроках математики можно использовать для ознакомления детей с новым материалом, его закрепления, повторения ранее изученного, для полного и глубокого осмысления и усвоения полученных знаний. Игры позволяют индивидуализировать работу на уроке, подбирать задания, посильные для каждого ученика, максимально развивать детские способности, они способствуют решению поставленной задачи [3].

Учащиеся наблюдают, сравнивают, классифицируют предметы по определенным признакам, абстрагируются от несущественных признаков, делают обобщения, они учатся выражать мнение в связной и понятной форме, используя математическую терминологию [3].

Создавая игровую ситуацию, согласно содержанию учебного материала, учитель четко планирует деятельность учащихся, направляет ее на достижение поставленной цели. Подобрав занятие согласно программе, он придает ему игровую форму, определяет соответствующие действия. Собственно игровой замысел, побуждает учащихся к участию в игре, и составляет ее основу [3].

Важно заранее подготовить дидактический материал для игры, продумать последовательность игровых действий, организацию своих воспитанников, продолжительность игры, ее контроль и суммирование. Математические игры для 1 класса рекомендуются на каждом уроке, когда ученики еще не привыкли к длительной, 
напряженной, чисто учебной деятельности и быстро утомляются. Во время игры они отдыхают, поскольку проходит умственное напряжение [3].

Игры, предлагаемые в начале урока, должны возбуждать мысль ученика, помогать ему сосредоточиться и выделить самое важное, нацелить на самостоятельную деятельность. Иногда на игре строится весь урок.

Однако заметим, что отдельные игры слишком возбуждают эмоции детей, надолго отвлекают их внимание от основной учебной цели занятия. Ведь первоклассники еще не умеют управлять своими эмоциями, произвольно переводя внимание, сосредоточиваться в нужный момент. Поэтому игры, вызывающие сильное эмоциональное возбуждение, желательно практиковать только в конце урока [3].

Чтобы игровая деятельность на уроке была эффективной и давала желаемые последствия, обязательно следует управлять ею, соблюдая следующие требования:

Проводить игру только тогда, когда каждый ученик обеспечен необходимым дидактическим материалом, четко осознал цель и последовательность действий.

Правила игры должны быть простыми и точно сформулированными. Материал игры посилен для всех детей.

Результат игры должен быть понятным каждому ребенку, непременно оцениваться, а ход ее контролироваться учителем. Подведение результатов игры должно быть четким и справедливым [3].

Недопустимо унижать достоинство ребенка, когда она обнаруживает неумение (обидные сравнения, насмешки и т.п.).

Четко объяснять содержание игры, ее правила, избегая многословия.

Если игра сложная, нужно проводить ее поэтапно, чтобы учащиеся поняли и усвоили сначала отдельные действия, а поэтому игру в целом и различные ее варианты.

Игра интересна только в том случае, если в ней принимает активное участие каждый ребенок. Длительное ожидание одной своей очереди снижает интерес к игре.

Весь игровой материал необходимо четко систематизировать и сгруппировать таким образом, чтобы им было удобно пользоваться. Например, мелкие предметы (цифры, знаки, монеты, кружочки, квадратики и т.д.) следует хранить в коробках с надписями или изображениями этих предметов. В конвертах - плоские геометрические фигуры, рисунки различных предметов и т.п. Их тоже нужно подписать или сверху наклеить соответствующее изображение. Целесообразно рассадить учеников (сделать это незаметно) так, чтобы за каждой партой сидели сильный ученик и слабее. А уровень знаний и умственного развития детей в рядах парт должно быть примерно одинаковым. Тогда шансы выиграть будут иметь ученики каждого ряда [3].

Математическая игра на уроке должна быть хорошо организована и целеустремлена. Прежде ученикам надо осознать правила - единые по форме для всех игр, чтобы постепенно выработался стереотип. Такие правила обязывают детей действовать строго по очереди или коллективно; отвечать по вызову, внимательно слушать ответ товарища, чтобы исправить его по необходимости, не повторяться: не мешать другим; честно признавать свои ошибки и т.д.. В этом заключается организационная роль правил игры. Кроме того, они являются средством управления игрой: указывается способ действий и их последовательность, формируются требования к поведению, регулируются взаимоотношения детей в игре [3].

Учитель все время контролирует деятельность класса, направляет игру, поощряет вопросами или репликами, незаметно поддерживая слабых детей, ободряя их, предотвращая возникновение конфликтов и тому подобное. Не следует увлекаться лишь дидактической целью игры, недооценивая ее воспитательного значения, потому что это приводит к тому, что ученики начинают хитрить, добиваясь успехов нечестным путем, не соблюдая правил игры, пренебрегая интересами коллектива. В зависимости 
от обстоятельств учитель должен найти время и указать ученику на такие проступки, объяснив, к чему это может привести (ухищрения, недобросовестное выполнение своих обязанностей). Однако не стоит прибегать к длительному морализаторству [3].

В игре обязательно участвуют все ученики класса. Поэтому задачи следует подбирать короткие и посыльные, избегая однообразия, предотвращая образование очереди игроков (чтобы включиться в игру), поскольку это снижает интерес, утомляет детей [3].

Сформулируем общие правила игры для учащихся в такой оживленной форме [3]: 1. Внимательно слушай и запоминай необходимые действия, их последовательность.

2. Помни: успех зависит от четкого осознания конечной цели. Не спеши выполнять задачи, недослушав до конца учителя. Поспешность так же вредна, как и излишнее промедление.

3. Внимательно слушай ответы товарищей, чтобы в случае необходимости что-то исправить или несколько дополнить.

4. Соблюдай свою очередь, не мешай товарищам, не делай ничего лишнего, будь дисциплинированным.

5. Честно признавай свои ошибки, если товарищи доказали, что ты неправ. Ошибиться может каждый.

6. Не хитри, не ищи нечестного пути для победы. Этим ты подводишь товарищей и теряешь свой авторитет.

Последний пункт учитель должен особо подчеркнуть и предостеречь, что даже в таком случае, когда все выполнено как следует, но хоть один ученик схитрил, то команда занимает последнее место. За правильностью, честностью в игре следит не только учитель, но и ученики [3].

Игровые ситуации на уроке математике может создать и сам учитель. Вот несколько примеров.

При выработке у первоклассников навыков счета целесообразно предложить задачу в такой игровой форме [3].

1. Учитель расставляет на наборном полотне карточки с изображениями различных предметов и предлагает посчитать отдельно животных, а затем овощи, фрукты и т.д..

2. Учитель хлопает в ладоши, ученики также хлопают приблизительно столько же раз и считают аплодисменты.

3. Учитель стучит указкой по столу несколько раз, а ученики, сосчитав стуки, молча поднимают карточку с соответствующей цифрой.

4. На доске записано число или прикреплена цифра из раздаточного материала. Задача: показать (поднять в руке) столько же палочек.

5. Счет детей в классе

Приемы зрительной, слуховой, двигательной наглядности, занимательные и доступные детям вопросы, загадки, задачи - шутки, моменты неожиданности, соревнования способствуют активизации мыслительной деятельности [4-5].

Большинство дидактических игр заключает в себе вопрос, задание, призыв к действию, например: кто верней и быстрей? Не зевай! Отвечай сразу! [7]

Значительная часть игр позволяет сделать то или иное обобщение, осознать только что изученное правило, закрепить, повторить полученные знания в единстве, в системе, в новых связях, что содействует более глубокому усвоению пройденного.

Например, при закреплении учащимися знания таблицы сложения часто используется игра «Поймай рыбку».

На доске висит таблица, на которой изображен аквариум с рыбками. На каждой рыбке записан пример. Двое учеников выходят к доске и по команде начинают решать примеры. Остальные ученики выполняют задание в тетрадях. По истечении времени, 
отведенного на вычисление, учащиеся сверяют свои ответы с доской. Тот из учеников у доски, кто решил примеров больше и не допустил ошибок, тот и поймал больше рыбок. Он и считается лучшим рыбаком.

Игра эта простая, но она позволяет в игровой форме повторить таблицу сложения, внести в урок элемент соревнования, что еще более способствует активизации деятельности учащихся, обязывает их быть более четкими, собранными, быстрыми.

Многие игры и упражнения строятся на материале различной трудности. Что дает возможность осуществить индивидуальный подход, обеспечить участие в одной и той же игре учащихся с разным уровнем знаний.

Например, дается самостоятельная работа в виде игры «Кто первый полетит в космос?». Поскольку это игра, учащиеся чувствуют себя свободно, а потому уверенно и с интересом приступают к работе.

Каждый получает карточку с заданием - задачей. Задача у всех одна и та же, но степень помощи к ее решению для каждого ученика оказывается разная. Так, например, хорошо подготовленным ученикам предлагается решить задачу по краткой записи, составив по ней выражение. Слабоуспевающим ученикам - составить задачу по краткой записи и закончить ее решение.

Объясняется цель игры: тот, кто решит задачу, может считать себя космонавтом. Так как, для того чтобы полететь в космос, надо хорошо знать математику.

На таких уроках ставится цель привития любви к математике у учащихся с сильными и слабыми математическими способностями. Каждый ученик, будь т девочка или мальчик, не могут оставаться равнодушными к космосу. Все стараются выполнить задание, все хотят быть космонавтами. Дидактические игры помогают более тесно увязать знания, полученные на уроке математики, с жизнью, сделать процесс повторения пройденного более разнообразным, воспитать потребность узнать, спросить.

Таким образом, включение в учебный процесс игры, создание на уроке игровой ситуации приводят к тому что учащиеся, увлеченные игрой, незаметно для себя и без особого напряжения приобретают определенные знания, умения и навыки по математике.

Однако игра не должна быть самоцелью, а должна служить средством развития интереса к математике. Чтобы она выполняла эту цель, при ее организации необходимо придерживаться следующих положений:

В процессе работы на уроке полезно включать логические игры, в которых путем несложных умозаключений можно предвидеть, предугадать необходимый результат, ответ. В этом их притягательная сила.

Первоклассника нетрудно заинтересовать математикой. Самое обычное решение примеров можно преподнести так, что работа эта не покажется детям скучной и утомительной. Для этого достаточно прижать упражнениям занимательный характер, включить в работу элементы соревнования. Форма игры захватывает детей, и они с удовольствием выполняют задание.

Приведем некоторые игры и занимательные упражнения, которые можно использовать в работе с классом почти на каждом уроке, начиная с первого года обучения. Проводятся они в течение 5-10 мин в начале или в конце урока в зависимости от цели и задачи данного занятия. Это, как правило, игры, в которых принимает активное участие весь класс или команды, тогда каждый ряд контролирует свою команду.

Вот, например, как проводятся некоторые игры.

«Кто скорее?» На доске записаны в три столбика примеры. По команде учителя к доске выходят по порядку от каждого ряда по одному ученику и берут мел. Учитель 
открывает примеры, и ученики приступают к выполнению действий. Решив пример, ученик кладет мел и садится на место. К доске выходит следующий ученик и решает пример и т.д. Выигрывает тот ряд, который быстрее и без ошибок решит все примеры. В случае одинаковых результатов учитывается организованность, дисциплина каждого ряда.

«Забей в ворота мяч» На доске нарисованы футбольные ворота, а на сетке записаны числа, например 24, 27, 28. Каждому ряду дается задание - составить за определенное время (5-6 мин) как можно больше примеров с данным ответом. Например, первый ряд записывает в своих воротах примеры с ответом 24, второй - с ответом 27, третий - с ответом 28.

Выигрывает команда, участники которой больше и верно запишут примеров с нужным ответом.

«Какая фигура исчезла?» На классной доске выставляются геометрические фигуры(не более 5 или 6 фигур), вырезанные из цветной бумаги или картона. Два ученика выходят к доске. Один из них внимательно рассматривает выставленные фигуры, стараясь их запомнить. Затем он отворачивается от доски, а другой ученик в это время прячет одну из фигур. Повернувшись лицом к доске, ученик пытается узнать, какая из геометрических фигур исчезла.

Игру можно проводить, не убирая фигуру, а переставляя ее. Тогда вопрос, естественно, будет звучать так: «Скажи, какая фигура переставлена?». Если ученик выиграл, т.е. правильно назвал геометрическую фигуру, которую спрятали или поменяли местами, он имеет право сам назвать следующих двух играющих.

Игру можно организовать в форме соревнования между двумя командами.

Дидактические игры часто бывают связаны с определенным сюжетом, который подсказывает само название игры: «Поймай рыбку», «Таблицу знаю», «Полет в космос», «Узнай, какая дорога ведет на Ореховку» и др.

Во многих дидактических играх, таких, как «Набери число», «Кто скорее?», «Лесенка», «Не зевай!» заложен элемент соревнования между группами, который усиливает эмоциональный характер игры. Причем соревнования лучше проводить на первенство среди ребят, сидящих в одном ряду. В этом случае дети стремятся не только сами хорошо выполнить задание, но и пробудить к этому своих товарищей, помочь им.

Большую помощь в формировании понятий больше, меньше, столько же оказывает игра «Сравни и скажи, где больше, меньше, одинаково».

На карточках (или на классной доске) нарисованы по две группы предметов, которые отличаются расположением, величиной и формой.

Детям предлагается внимательно посмотреть на обе группы предметов, сравнить их ответить на вопрос: каких предметов больше, меньше, одинаково? Вопрос решается путем пересчета предметов обеих групп и сравнения чисел.

Если игра проводится у доски, то используется прием зачеркивания. Грибы зачеркнуты все, а треугольник остался не зачеркнутым, без пары. Учащиеся делают вывод, что треугольник на 1 больше, чем грибов, а грибов соответственно на 1 меньше, чем треугольников.

Такую же работу в форме игры можно проводить на наборном полотне с разным дидактическим материалом.

Интересны игры в угадывании числа, развивающие навык беглого счета, различные занимательные квадраты (квадраты с заполенными клетками, квадраты с частично заполненными клетками, квадраты с незаполненными клетками), лабиринты, цепочки, разнообразные варианты игр «Молчанка», «Чей букет лучше?».

На доске - три столбика примеров:

$$
\text { 93:31 } \quad 42: 14 \quad 96: 6
$$




$\begin{array}{rrr}81: 3 & 36: 2 & 69: 3 \\ 19 * 4 & 2 * 36 & 5 * 20 \\ 12 * 6 & 15 * 4 & 15 * 3\end{array}$

Рядом на столе лежат карточки с ответами. На обратной стороне карточек нарисованы цветы. Трое участников выходят к доске и по команде начинают решать примеры. Остальные учащиеся записывают ответы в тетрадях. Когда истекает время, отведенное на вычисление, учащиеся сверяют свои решения с доской, устанавливают правильность выполненного задания и разрешают ученикам у доски составить букет. Каждый ученик берет столько карточек с цветами, сколько верно он решил примеров. Букет лучший тот, у кого больше карточек.

У учащихся начальных классов большой популярностью пользуются игры «Лучший счетчик», «Кто вернее и быстрее?», «Кто первый догонит пилота?», «Какая команда лучше?», «Не зевай!», «Угадай число», «Хватит ли всем?».

Такие игры, кроме решения учебных задач, способствуют воспитанию нравственных качеств личности, привитию навыков правильного поведения в коллективе. На каждого ученика ложиться ответственность за результаты игры команды. Это подтягивает дисциплину учащихся.

При проведении дидактических игр на уроке математики необходимо продумывать следующие вопросы:

Цель игры. Какие умения и навыки по математике формируются в процессе игры. Какие воспитательные цели преследуются в процессе игры (воспитывать волевые качества, взаимопомощь, доверие, дружбу, чувство товарищества, умение подчинять свои личные интересы интересам группы и др.). Материалы и пособия для игры. Знакомство с правилами игры в минимально короткий срок. Время проведения игры. Организация детей (соревнования отдельных учеников, команд, участие всего класса). Изменение правил игры в целях активизации класса. Подведение итогов игры.

Хорошая игра похожа на хорошую работу, писал А. С. Макаренко. Вот почему игре уделяется должное внимание в учебно - воспитательном процессе детей.

\section{Литература:}

1. Журналы «Начальная школа» за 1989 год.

2. Лебедь Ж.В. Приёмы познавательной деятельности при формировании вычислительных навыков. Методический бюллетень №1. [Электронный ресурс]. URL: http://www.schule-32.narod.ru/ped op1.html (дата обращения 01.02.2014).

3. Математические игры в 1 классе. [Электронный pecypc]. URL: http://schoolbox.ru/obrazovatelnye-statyi/interesno-ob-obrazovanii/858-matematicheskie-igri-v-1-

klasse.html (дата обращения 07.02.2014).

4. С. Е. Гаврина, Н. Г. Кутявина, И. Г. Топоркова, С. В. Щербинина «Весёлые задачки для маленьких умников». - М., 2004, -32с.

5. Уткина Н. Г. Изучение трудных тем по математике в 1-3 классах. Москва, Просвещение, 1992. -60с.

6. Т.И. Тарабарина, Н.В. Елкина И учеба, и игра: математика. Ярославль, «Академия развития», 2006. -240с.

7. Дидактические игры для младших школьников. -2010. [Электронный ресурс]. URL: http://www.menobr.ru/materials/307/4746/ (дата обращения 05.02.2014).

8. Эльконин Д.Б. Психология игры. - 2-е изд. - М.: Туманит, изд. центр ВЛАДОС, 1999. 9. ГДЗ по Математике. 3 класс. Петерсон Л.Г. 2012г. -360с.

10. Решебник (ГДЗ) Математика, 3 класс [3 части] (Л.Г. Петерсон) 2011. -254c. 11. Рутюнян Е., Левитас Г. Занимательная математика. 1-5 классы. - М.: Аст-пресс книга, 1999, -368c. 